\title{
Diabetes Self-Care Activities and Glycaemic Control among Adults with Type 2 Diabetes in Sri Lanka: A Cross-Sectional Study
}

\author{
Meerigama Arachchige Rasoda Saumika1 ${ }^{\text {, Thamara Dilhani Amarasekara2 }}{ }^{\text {, Rasika Jayasekara }}{ }^{3}$ \\ ${ }^{1}$ Department of Nursing, Faculty of Health Sciences, The Open University of Sri Lanka, Sri Lanka \\ ${ }^{2}$ Department of Nursing\& Midwifery, Faculty of Allied Health Sciences, University of Sri Jayewardenepura, Sri Lanka \\ ${ }^{3}$ School of Nursing and Midwifery, University of South Australia, South Australia, Australia \\ Email: thamaraamarasekara@yahoo.com,thamara@sjp.ac.lk
}

How to cite this paper: Saumika, M.A.R., Amarasekara, T.D. and Jayasekara, R. (2019) Diabetes Self-Care Activities and Glycaemic Control among Adults with Type 2 Diabetes in Sri Lanka: A Cross-Sectional Study. Journal of Biosciences and Medicines, 7, 99-111.

https://doi.org/10.4236/jbm.2019.75013

Received: December 27, 2018

Accepted: May 14, 2019

Published: May 17, 2019

\begin{abstract}
The prevalence of Type 2 Diabetes Mellitus (T2DM) and its complications continue to rise across the globe including Sri Lanka. Diabetes Self-care activities (DSCA) are promising behaviors to reduce complications and to achieve good glycaemic control. There is a lack of data regarding DSCA and its association with glycaemic control among adults with T2DM in Sri Lanka. A descriptive cross-sectional study was conducted among purposively selected adults with T2DM $(\mathrm{n}=300)$ in a teaching hospital, Sri Lanka to determine the association between DSCA and glycaemic control. Apre-tested interviewer-administered questionnaire which includes socio-demographic, diabetes-related information and Summary of Diabetes Self-care activities questionnaire was used to collect data. Data were analyzed by using descriptive statistics and Chi-square test. General diet (Healthy eating plan) ( $\mathrm{OR}=3.04$, $95 \% \mathrm{CI}=1.04-8.88, \mathrm{p}=0.034)$, Physical activities $(\mathrm{OR}=2.26,95 \% \mathrm{CI}=1.29$ 3.97, $\mathrm{p}=0.004)$, Medication adherence $(\mathrm{OR}=2.87,95 \% \mathrm{CI}=1.24-6.64, \mathrm{p}=$ 0.011 ) were significantly associated with $\mathrm{HbAlc}$. Medication adherence was significantly associated with poor fasting blood sugar (FBS) (OR $=1.90,95 \%$ $\mathrm{CI}=1.07-3.37, \mathrm{p}=0.028$ ). The findings highlight the need for health professionals to implement health education programs on diabetes self-care activities for adults with T2DM to enhance their adherence to DSCA, as well as to maintain glycemic control.
\end{abstract}

\section{Keywords}

Diabetes Self-Care Activities, Glycemic Control, Adults, Type 2

Diabetes Mellitus, Sri Lanka 


\section{Introduction}

T2DM has become a global epidemic that affects over 377 million people worldwide, with estimated prevalence rates rising to an alarming 642 million people by 2040 [1]. Most people with diabetes live in low- and middle-income countries, and these countries will experience the highest increase in cases of diabetes over the next two decades [2]. Diabetes Mellitus (DM) is a group of illnesses characterized by high blood glucose levels that result from defects in the body's ability to produce and/or use insulin. T2DM is the most common form of diabetes in which the body is unable to produce adequately to overcome insulin resistance and affects various organs and systems [3]. In Sri Lanka, DM is a significant health problem; with an unprecedented current level of prevalence [4]. According to a recent study, the age-adjusted prevalence for T2DM was 20.3\% for males and 19.8\% for females in an urban cohort, and of those diagnosed with T2DM, only23.8\% were optimally controlled [5]. However glycaemic control has an effect on improving diet, exercise, medication, foot care efficacy and behaviors [6]. As there is no cure for diabetes, self-care activities are promising activities in blood sugar control among patients with T2DM. In Sri Lanka, the majority of the adults with T2DM did not involve recommended DM management strategies including restricting refine sugar, regular exercises or checking blood sugar regularly [7] and the majority of adults with T2DM did not achieve desired glycaemic control [8].

\section{Literature Review}

Several previous studies have shown that high levels of patients adherence to diabetes self-care behaviors resulted in better metabolic control [9] [10] [11] [12] and self-care skills play a crucial role in optimal diabetes control [13]. Diabetes self-care Activities (DSCA) include a range of activities such as self-monitoring of blood glucose, eating a healthy diet, being physically active, taking the recommended medication and consulting health care professionals [14]. A Chinese study revealed that; effective-patient communication, social support, and higher self-efficacy were associated with performing diabetes self-care behaviors; that were directly linked to glycaemic control [15]. A study suggested that interactive health education programs should be introduced to increase patient adherence to the treatment, and the importance of family members' involvement in encouraging patients' glycaemic control [16].

According to studies, Sri Lanka is among the countries with the highest diabetes prevalence rates in the world [17]. Sri Lankan studies revealed that one in five adults has either diabetes or pre-diabetes condition [18]. A national survey conducted in 2005 to 2006, explored that the prevalence of T2DM was twice as high in persons from urban areas (16.4\%) as compared to persons from rural areas (8.7\%) [18]. In 2016, the number of death attribute due to the high blood glucose level in Sri Lanka was 4660 males and 2470 females of the age limit between 30 to 69 which is significantly higher compared to the universal figure of 
2860 males and 1740 females [19]. In the same year, the prevalence of diabetes in Sri Lanka was among males $7.3 \%$ females, and 8.4\% [19]. Further, the researchers revealed that the incidence of diabetes risk factors such as the prevalence of overweight among males was $18.9 \%$, and females $32.9 \%$ [19]. Prevalence of obesity among men was $3.5 \%$ and among women was $10.0 \%$. Prevalence of physical inactivity is higher in women (30.2\%) compared with men (16.9\%) [19]. There is an apparent deficiency in self-care practices; medication adherence, dietary practices, physical exercises, foot care practices and identification and prevention of complications among patients with diabetes; however the majority of the participants in their study preferred to learn more about how to control their DM [20]. Self-care activities are much crucial to glycaemic control among adults with T2DM. Hence it is important to determine the association between DSCA and the glycaemic control.

\section{Method}

\subsection{Design}

A descriptive, cross-sectional design was used and 300 purposively selected adults with T2DM were selected based on inclusion and exclusion criteria.

\subsection{Participants and Setting}

This study was conducted at a diabetic clinic at Sri Jayewardenepura General Hospital (SJGH), Colombo, Sri Lanka which provides care for the large number of adults with T2DM. The Diabetic clinic runs only 2 days per week (Wednesday and Thursday) and usually, 30 patients attend the clinic per day.

This study included adult participants (age 18 and above) with a diagnosis of T2DM, and a minimum duration of $>6$ months of diagnosis was required because the participants need some time to adapt to their illness and to practice diabetes self-care. Adults with T2DM who had physical or cognitive impairments, pregnant women, adults who have diagnosed with diabetes less than six months and adults who were severely ill were excluded from the study.

\subsection{Data Collection}

An Interviewer-administered questionnaire was developed by the researcher, using the revised version of the Summary of Diabetes Self-care Activities (SDSCA) that is used to measure self-care activities of diabetic patients [14]. The author permission was obtained to use the SDSCA for this study. The questionnaire used in this study contains three parts namely: Part-A sociodemographic information, Part-B Diabetes related information (duration of having diabetes, family history of diabetes, $\mathrm{HbA1c}$ investigations etc.) and Part $\mathrm{C}$ consisted of a validated summary of diabetes self-care activities (SDSCA). The SDSCA scale is a self-reporting measure of the DSCA: diet, exercise, blood glucose testing, medication taking, foot care, and smoking behaviour. The SDSCA asked the participants to report the frequency in which they perform the above-mentioned 
DSCA over the past 7 days. If they were sick during the past 7 days, they were asked to reflect on the 7 days before they became ill. The questionnaire was pre-tested among 10 patients with T2DM to determine acceptability, feasibility, comprehensibility and appropriateness and these participants did not participate in this study.

\subsection{Ethical Considerations}

Ethical approval was obtained from the Ethics Review Committee of Faculty of Medical Sciences University of Sri Jayewardenepura, Sri Lanka and Ethics Review Committee of SJGH. Without disturbing to the clinic routines, the convenient time for participants was used for data collection. Informed written consent was obtained from all participants after a detailed explanation of the purpose and procedures used for the study. All the participants were informed that the privacy and confidentiality would be ensured during all steps of the study. Hence, all the participants had the right to avoid participation at any time of the study. All data collected were treated as private and confidential to maintain anonymity. Data were stored on password secure digital storage which could only be accessible for the investigators.

\subsection{Data Analysis}

Sample characteristics were analysed by using descriptive statistics, by using SPSS (Statistical Package for Social Sciences) 20.0 version. The association between level of self-care practices, HbA1c, FBS, BMI, and socio-demographic factors was tested by using Pearson's Chi-square test. Results were presented by using descriptive statistics including percentages and graphs. A confidence value of $95 \%$ and the probability of $<0.05$ were considered statistically significant for all tests.

\section{Results}

\subsection{Socio-Demographic Characteristics of Adults with T2DM}

As presented in Table 1 the majority of participants were female $(n=206$; $68.7 \%)$, and $253(84.3 \%)$ were married. Nearly $48 \%(n=143)$ participants belonged to the 50 - 64 age group. More than half (51.3\%) were educated to Advance Level (high school) and above and $60 \%$ had an income more than Rs $40,000(46.3 \%, 139)$ were housewives, and $84(28 \%)$ were retired.

\subsection{Diabetes-Related Information of Adults with T2DM}

Clinical characteristics of adults with T2DM are presented in Table 2. Nearly half of participants $(44.7 \%, 134)$ had been diagnosed with T2DM for 2 - 10 years. Most participants (73\%) had a family history of diabetes. More than half $(51.7 \%)$ had a normal BMI (18.5 - 24.99) with a mean of 24.66 (standard deviation [SD] = $4.51)$. Nearly half of participants $(52.7 \%, 158)$ adults had a good fasting blood glucose level ( $\leq 126 \mathrm{mg} / \mathrm{dl})$; however, $75.7 \%$ of participants demonstrated $\mathrm{HbA} 1 \mathrm{c}$ 
Table 1. Socio-demographic characteristics of adults with T2DM $(n=300)$.

\begin{tabular}{|c|c|c|}
\hline Characteristics. & Frequency & Percent (\%) \\
\hline \multicolumn{3}{|l|}{ Gender } \\
\hline Female & 206 & 68.7 \\
\hline Male & 94 & 31.3 \\
\hline \multicolumn{3}{|l|}{ Age (years) } \\
\hline $18-29$ & 8 & 2.7 \\
\hline $30-49$ & 59 & 19.7 \\
\hline $50-64$ & 143 & 47.7 \\
\hline $65-70$ & 67 & 22.3 \\
\hline$\geq 71$ & 23 & 7.7 \\
\hline \multicolumn{3}{|l|}{ Ethnicity } \\
\hline Sinhala & 273 & 91.0 \\
\hline Tamil & 13 & 4.3 \\
\hline Muslim & 12 & 4.0 \\
\hline Burgher & 2 & 0.7 \\
\hline \multicolumn{3}{|l|}{ Educational status } \\
\hline Not attained to the school & 1 & 0.3 \\
\hline Grade 1 - 5 & 3 & 1.0 \\
\hline Grade 6 - 10 & 40 & 13.3 \\
\hline Ordinary level & 102 & 34.0 \\
\hline Advanced level & 99 & 33.0 \\
\hline Higher education & 55 & 18.3 \\
\hline \multicolumn{3}{|l|}{ Marital status } \\
\hline Single & 10 & 3.3 \\
\hline Married & 253 & 84.3 \\
\hline Other & 37 & 12.3 \\
\hline \multicolumn{3}{|l|}{ Occupation } \\
\hline Professional & 21 & 7.0 \\
\hline Technical \& clerical & 13 & 4.3 \\
\hline Vendors \& sellers & 21 & 7.0 \\
\hline Skilled manual workers & 12 & 4.0 \\
\hline Unskilled manual workers & 5 & 1.7 \\
\hline Retired & 84 & 28.0 \\
\hline Unemployed & 5 & 1.7 \\
\hline Housewife & 139 & 46.3 \\
\hline \multicolumn{3}{|c|}{$\begin{array}{l}\text { Average monthly income for the family } \\
\text { (In Sri Lankan Rupees) }\end{array}$} \\
\hline Less than $29,999 \mathrm{Rs}$ & 25 & 8.3 \\
\hline $30,000 \mathrm{Rs}-40,000 \mathrm{Rs}$ & 95 & 31.7 \\
\hline $40,001 \mathrm{Rs}-60,000 \mathrm{Rs}$ & 109 & 36.3 \\
\hline $60,001 R s-80,000 R s$ & 48 & 16.0 \\
\hline More than $80,001 \mathrm{Rs}$ & 23 & 7.7 \\
\hline
\end{tabular}


Table 2. Diabetes related information of adults with T2DM $(n=300)$.

\begin{tabular}{|c|c|c|}
\hline Characteristics. & Frequency & Percent (\%) \\
\hline \multicolumn{3}{|l|}{ Duration of diabetes } \\
\hline $6-12$ months & 11 & 3.7 \\
\hline 1 - 2 years & 30 & 10 \\
\hline $2-10$ years & 134 & 44.7 \\
\hline$>10$ years & 125 & 41.7 \\
\hline \multicolumn{3}{|l|}{$\begin{array}{l}\text { Family history of Type } 2 \\
\text { diabetes mellitus }\end{array}$} \\
\hline Yes & 219 & 73 \\
\hline No & 80 & 26.7 \\
\hline Don't know & 1 & 0.3 \\
\hline BMI (body mass index) & 23 & 7.7 \\
\hline Under weight $<18.50$ & 155 & 51.7 \\
\hline Normal 18.50 - 24.99 & 85 & 28.3 \\
\hline Overweight 25 - 29.99 & 37 & 12.3 \\
\hline \multicolumn{3}{|l|}{ Obese $\geq 30$} \\
\hline \multicolumn{3}{|l|}{ HbAlc value. } \\
\hline Good Control < 7\% & 73 & 24.3 \\
\hline Poor control. $\geq 7 \%$ & 227 & 75.7 \\
\hline \multicolumn{3}{|l|}{ Fasting blood sugar value. } \\
\hline Good Control $\leq 126 \mathrm{mg} / \mathrm{dl}$ & 158 & 52.7 \\
\hline Poor control > $126 \mathrm{mg} / \mathrm{dl}$ & 142 & 47.3 \\
\hline \multicolumn{3}{|l|}{ Medication } \\
\hline Oral pills only & 216 & 72.0 \\
\hline Oral and Insulin & 71 & 23.7 \\
\hline Insulin only & 13 & 4.3 \\
\hline
\end{tabular}

value ( $\geq 7 \%$ ). Majority of participants (72\%) controlled their blood glucose levels using oral hypoglycaemic agents.

\subsection{Summary of Diabetes Self-Care Activities of Adults with T2DM}

According to the results, 262 (87.4\%) of the adults with T2DM followed General Diet (Healthy eating plan) and $170(56.6 \%)$ not followed a specific diet (fruits and vegetables, less meat and dairy products), 3 or more than 3 days from 7 days. Exercise regimen (30 minutes and specific exercise) was followed by 166 (55.3\%) participants on 3 or more than 3days in the past 7 days, and 71 (23.7\%) did not follow exercise regimen in even a single day. More than half (60.3\%) of the participants did not perform self-monitoring of blood glucose (SMBG) even a single day while 59 (19.7\%) performed SMBG 3 or more than 3 days in the past 7 days. Nearly half (49.7\%) did not perform foot care (Checked feet, wash feet, soak feet, dry between toes after washing) even a single in the past seven days. 
Only $131(43.7 \%)$ followed foot care 3 or more than 3days in the past 7 days. Majority of the participants (80\%) reported adhering to medication regularly. A small percentage of the participants smoked at least 1 puff $(4.7 \%)$ in the past 7 days.

Socio-demographic characteristics are not significantly associated with HbAlc, FBS, Diet, SMBG and Medication adherence. Associations of socio-demographic characteristics with physical activity are presented in Table 3. People; age $\leq 49$ years had good physical activity when compared to people $\geq 50$ years. Age was significantly associated with physical activity $(\mathrm{OR}=2.46$, $95 \% \mathrm{CI}=1.37-4.44, \mathrm{p}=0.002)$. As shown in Table 4 female participants showed good foot care practices when compared to male participants. Gender was significantly associated with foot care $(\mathrm{OR}=1.68,95 \% \mathrm{CI}=1.01-2.78, \mathrm{p}=$ $0.043)$.

\subsection{Associations of DSCA with Glycemic Control}

Associations of DSCA with Glycemic control are presented in Table 5. Participants who have followed the general diet and specific diet showed good glycemic control when compared to adults with poor self-care activities in general diet and specific diet. General diet was significantly associated with $\mathrm{HbAlc}(\mathrm{OR}=$ $3.04,95 \% \mathrm{CI}=1.04-8.88, \mathrm{p}=0.034)$. Physical activities also significantly associated with $\mathrm{HbA1c}(\mathrm{OR}=2.26,95 \% \mathrm{CI}=1.29-3.97, \mathrm{p}=0.004)$. Both general diet $(\mathrm{OR}=3.64,95 \% \mathrm{CI}=1.70-7.79, \mathrm{p}=0.000)$ and specific $\operatorname{diet}(\mathrm{OR}=2.37,95 \% \mathrm{CI}=$

Table 3. Associations of socio-demographic demographic characteristics with physical activity $(\mathrm{n}=300)$.

\begin{tabular}{|c|c|c|c|c|c|}
\hline & \multirow{2}{*}{$\begin{array}{c}\text { Good } \\
(3-7 \text { days })\end{array}$} & \multirow{2}{*}{$\begin{array}{c}\text { Poor } \\
(0-2 \text { days })\end{array}$} & \multirow{2}{*}{ OR } & \multicolumn{2}{|c|}{$95 \% \mathrm{CI}$} \\
\hline & & & & Lower & Upper \\
\hline \multicolumn{6}{|l|}{ Age } \\
\hline $18-49$ (Years) & $48^{*}$ & 19 & 2.46 & 1.37 & 4.44 \\
\hline$\geq 50$ (Years) & 118 & 115 & & & \\
\hline \multicolumn{6}{|l|}{ Gender } \\
\hline Female & 121 & 85 & 1.55 & 0.95 & 2.53 \\
\hline Male & 45 & 49 & & & \\
\hline \multicolumn{6}{|l|}{ Education Level } \\
\hline$\leq$ Ordinary level & 75 & 71 & 0.73 & 0.46 & 1.16 \\
\hline$>$ Ordinary level & 91 & 63 & & & \\
\hline \multicolumn{6}{|l|}{ Monthly income } \\
\hline$\leq 40,000 \mathrm{Rs}$ & 66 & 54 & 0.98 & 0.61 & 1.56 \\
\hline$\geq 40,001 \mathrm{Rs}$ & 100 & 80 & & & \\
\hline \multicolumn{6}{|l|}{ Marital status } \\
\hline Married & 141 & 112 & 1.108 & 0.59 & 2.07 \\
\hline Single and Other & 25 & 22 & & & \\
\hline
\end{tabular}


Table 4. Associations of Socio-demographic demographic characteristics with Foot care $(\mathrm{n}=300)$.

\begin{tabular}{|c|c|c|c|c|c|}
\hline & \multicolumn{5}{|c|}{ Foot care } \\
\hline & \multirow{2}{*}{$\begin{array}{c}\text { Good } \\
(3-7 \text { days })\end{array}$} & \multirow{2}{*}{$\begin{array}{c}\text { Poor } \\
(0-2 \text { days })\end{array}$} & \multirow{2}{*}{ OR } & \multicolumn{2}{|c|}{$95 \% \mathrm{CI}$} \\
\hline & & & & Lower & Upper \\
\hline \multicolumn{6}{|l|}{ Age } \\
\hline $18-49$ (Years) & 28 & 39 & 0.91 & 0.52 & 1.57 \\
\hline$\geq 50$ (Years) & 103 & 130 & & & \\
\hline \multicolumn{6}{|l|}{ Gender } \\
\hline Female & $98^{*}$ & 108 & 1.68 & 1.01 & 2.78 \\
\hline Male & 33 & 61 & & & \\
\hline \multicolumn{6}{|l|}{ Education Level } \\
\hline$\leq$ Ordinary level & 56 & 90 & 0.66 & 0.41 & 1.04 \\
\hline$>$ Ordinary level & 75 & 79 & & & \\
\hline \multicolumn{6}{|l|}{ Monthly income } \\
\hline$\leq 40,000 \mathrm{Rs}$ & 53 & 67 & 1.03 & 0.65 & 1.65 \\
\hline$\geq 40,001 \mathrm{Rs}$ & 78 & 102 & & & \\
\hline \multicolumn{6}{|l|}{ Marital status } \\
\hline Married & 108 & 145 & 0.78 & .42 & 1.45 \\
\hline Single and Other & 23 & 24 & & & \\
\hline
\end{tabular}

${ }^{*} \mathrm{p}<0.05,{ }^{* *} \mathrm{p}<0.001$ level of significance.

$1.48-3.79, \mathrm{p}=0.000)$ were highly significant with FBS. Medication adherence was significantly associated with both $\mathrm{HbA1c}(\mathrm{OR}=2.87,95 \% \mathrm{CI}=1.24-6.64, \mathrm{p}=$ $0.011)$ and FBS $(\mathrm{OR}=1.90,95 \% \mathrm{CI}=1.07-3.37, \mathrm{p}=0.028)$. Other DSCA outcomes are not significantly associated with Glycemic control.

\section{Discussion}

Even though this study findings clearly indicate more than half of the participants had good FBS level; the majority of the participants had poor HbAlc value. Results from other studies have also reported poor glycaemic control among adults with T2DM.According to another Sri Lankan study, most participants did not achieve the recommended fasting blood glucose level $(<126$ $\mathrm{mg} / \mathrm{dL}$ ) [8]. Iranian study also indicated $42.9 \%$ did not reach the target FBS level [21]. In this study, the majority of the participants had a family history of diabetes. Another cross-sectional national survey which was conducted among 5000 adults in Sri Lanka have also shown, the prevalence of diabetes was significantly higher in patients with a family history $(23.0 \%)$ than those without $(8.2 \%)$ family history ( $\mathrm{p}<0.001$ ) [22]. The current study findings also revealed that more than half (51.7\%) had a healthy BMI (18.5 - 24.99). This finding is consistent with another study that showed nearly half $(48.3 \%)$ of the study participants had a healthy BMI (18.0 - 24.9) [8]. 
Table 5. Association of DSCA with glycemic control $(n=300)$.

\begin{tabular}{|c|c|c|c|c|c|c|c|c|c|c|}
\hline & \multicolumn{5}{|c|}{ Glycemic control (HbAlc) } & \multicolumn{5}{|c|}{ Glycemic control (FBS) } \\
\hline & \multirow{2}{*}{$\begin{array}{c}\text { Good } \\
\text { Control } \\
<7 \%\end{array}$} & \multirow{2}{*}{$\begin{array}{c}\text { Poor } \\
\text { control } \\
\geq 7 \%\end{array}$} & \multirow[b]{2}{*}{ OR } & \multicolumn{2}{|c|}{$95 \% \mathrm{CI}$} & \multirow{2}{*}{$\begin{array}{c}\text { Good } \\
\text { Control } \\
\leq 126 \mathrm{mg} / \mathrm{dl}\end{array}$} & \multirow{2}{*}{$\begin{array}{c}\text { Poor } \\
\text { control } \\
>126 \\
\mathrm{mg} / \mathrm{dl}\end{array}$} & \multirow{2}{*}{ OR } & \multicolumn{2}{|c|}{$95 \% \mathrm{CI}$} \\
\hline & & & & Lower & Upper & & & & Lower & Upper \\
\hline \multicolumn{11}{|l|}{ General Diet } \\
\hline $\begin{array}{l}\text { Good } \\
\text { (3 - } 7 \text { days) }\end{array}$ & $69^{*}$ & 193 & 3.04 & 1.04 & 8.88 & $148^{* *}$ & 114 & 3.64 & 1.70 & 7.79 \\
\hline $\begin{array}{l}\text { Poor } \\
\text { (0 - } 2 \text { days })\end{array}$ & 4 & 34 & & & & 10 & 28 & & & \\
\hline \multicolumn{11}{|c|}{ Specific Diet } \\
\hline $\begin{array}{l}\text { Good } \\
\text { (3 - } 7 \text { days) }\end{array}$ & 36 & 94 & 1.38 & 0.81 & 2.34 & $84^{* *}$ & 46 & 2.37 & 1.48 & 3.79 \\
\hline $\begin{array}{l}\text { Poor } \\
\text { (0 - } 2 \text { days })\end{array}$ & 37 & 133 & & & & 74 & 96 & & & \\
\hline \multicolumn{11}{|l|}{$\begin{array}{l}\text { Physical } \\
\text { activities. }\end{array}$} \\
\hline $\begin{array}{l}\text { Good } \\
\text { (3 - } 7 \text { days) }\end{array}$ & $51^{*}$ & 115 & 2.26 & 1.29 & 3.97 & 90 & 76 & 1.15 & 0.73 & 1.81 \\
\hline $\begin{array}{l}\text { Poor } \\
\text { (0 - } 2 \text { days })\end{array}$ & 22 & 112 & & & & 68 & 66 & & & \\
\hline \multicolumn{11}{|l|}{ SMBG } \\
\hline $\begin{array}{l}\text { Good } \\
\text { (3 - } 7 \text { days) }\end{array}$ & 10 & 49 & 0.58 & 0.28 & 1.21 & 32 & 27 & 1.08 & 0.61 & 1.92 \\
\hline $\begin{array}{l}\text { Poor } \\
\text { (0 - } 2 \text { days })\end{array}$ & 63 & 178 & & & & 126 & 115 & & & \\
\hline \multicolumn{11}{|l|}{ Foot Care } \\
\hline $\begin{array}{l}\text { Good } \\
\text { (3 - } 7 \text { days) }\end{array}$ & 36 & 95 & 1.35 & 0.80 & 2.30 & 72 & 59 & 1.18 & 0.75 & 1.86 \\
\hline $\begin{array}{l}\text { Poor } \\
\text { (0 - } 2 \text { days })\end{array}$ & 37 & 132 & & & & 86 & 83 & & & \\
\hline \multicolumn{11}{|l|}{$\begin{array}{l}\text { Medication } \\
\text { adherence }\end{array}$} \\
\hline $\begin{array}{l}\text { Good } \\
\text { (All } 7 \text { days) }\end{array}$ & ${ }^{*} 66$ & 174 & 2.87 & 1.24 & 6.64 & ${ }^{\star} 134$ & 106 & 1.90 & 1.07 & 3.37 \\
\hline $\begin{array}{l}\text { Poor } \\
(0-6 \text { days })\end{array}$ & 7 & 53 & & & & 24 & 36 & & & \\
\hline
\end{tabular}

In the present study, even though the majority $(87.3 \%)$ of the adults followed General Diet 3 or more than 3 days in the past 7 days (Healthy eating plan), $56.7 \%$ not observed specific diet 3 or more than 3 days in the past 7 days. As the Sri Lankan diet is high in calories from carbohydrates, the main message for dietary change should focus on the reduction of rice consumption with supple- 
mentation of more portions of vegetables and green leaves [23]. However, a Sri Lankan study has shown the majority of participants (71.7\%) practised some dietary control [8]. According to another Sri Lankan study, among the participants, $56.7 \%$ had poor dietary practices in relation to T2DM [21].

The current study also revealed more than half of participants $(55.3 \%)$ followed exercise regimen on 3 or more than 3 days in the past 7 days. Even though adults with T2DM have poor knowledge regarding exercise, the majority had an adequate level of physical activity during their daily activities, and they have a positive attitude towards physical activity [24]. In a Sri Lankan study, among the participants, $34.56 \%$ followed the recommended exercise [21]. However, a Sri Lankan study has shown the majority of participants (85.2\%) did not practice any form of exercise [8]. In this study more than half of the participants not performed SMBG even a single day. According to another Sri Lankan study of 146 adults with T2DM, only 5 (3.6\%) have practised SMBG (at least monthly) [25].

Nearly half $(49.7 \%)$ did not perform foot care even a single day in the past seven days. Only $43.7 \%$ followed foot care 3 or more than 3 days in the past 7 days. In similar to the present study another Sri Lankan study also showed a large proportion $(75.3 \%)$ of the participants have not engaged in foot care adequately [21]. However, in the current study, a majority of the participants who participated in foot care were women. This may be due to, females more concern of their body and as most of the women in the sample are housewives as they have more time to engage foot care practices. In Oman, of 350 adults with T2DM, 73.9\% followed foot care practices and Omani adults' foot care practices were high when comparing to the current study [26]. This may be due to lack of foot care clinics in Sri Lanka. As similar to the present study, the same Omani survey has shown, significant associations between gender and foot care [26].

Even though the present study showed the majority of the participants (80\%) adhered to medication regularly, in contrast to these results another Sri Lankan study revealed, among the participants, $59.73 \%$, showed poor medication practices [21]. According to the Omani study medication adherence was $77 \%, 3$ or more than 3 days in the past 7 days [26]. The Omani study further reviled, less than half percentage (45.5\%) of the adults smoked at least 1 puff in the past 7 days [26]. In contrast to this study, among the Omani adults smoking was high. This may be due to the Sri Lankan government's new legislation that enforced to include graphic warnings covering $60 \%$ of the surface area of packets of cigarettes. A Sri Lankan study also reviled $71.93 \%$ of the 119 participants were of the view that the demonstrated pictorial warnings would persuade the smokers to give up smoking [27]. In this study, general diet, physical activity and medication adherence were significantly associated with HbAlc. According to the results of a cross-sectional study; its bivariate analysis indicated the same three variables were significantly associated with HbAlc: adherence to diet, physical exercise, and medication-taking regimen [16]. 
This study had some limitations in the assessment of glycaemic control, in that FBS and HbAlc were done in different laboratories. In Sri Lanka, such testing might not have uniform standards. The study was conducted in a Colombo based teaching hospital, and there is reduced the ability to generalize findings to the whole country. As weight and height also recorded by patient's medical records, inconsistency may be high.

\section{Conclusion and Implications for Practice}

According to the findings, the majority of the participants followed the General Diet and more than half not followed a specific diabetic diet. A considerable amount of adults did not pursue an exercise regimen for even a single day. More than half of the participants did not perform SMBG even a single day. Nearly half of the participants did not perform foot care even a single in the past seven days. Majority of the participants, $(80 \%)$ reported adhering to recommended medication regularly. Nearly half of the participants had a good fasting blood glucose level $(\leq 126 \mathrm{mg} / \mathrm{dl})$ while the majority $(75.7 \%)$ demonstrating poor HbAlc value $(\geq 7 \%)$. Both general Diet and specific diet were highly significant with FBS. Physical activities were significantly associated with HbA1C. Female participants showed more adherence to foot care practices compared with male participants. Age was associated with considerably physical activities. Thus all these findings indicate that adults with good control of HbAlc and FBS reported better adherence to DSCA.

The findings prove that there is an urgent need for improving DSCA among adults with T2DM. This study can guide diabetes nurse educators to understand the extent to which different self-care behaviors that affect glycaemic control. Health educational interventions are necessary to improve glycaemic control. Most of the adults' SMBG practice was poor. This may be due to financial cost. Therefore health policies should introduce to facilitates SMBG. We suggest further improvement into this model with a prospective and longitudinal study to observe the association between SDSCA and HbAlc in the long term.

\section{Acknowledgements}

Deep gratitude is expressed to the study participants for their participation and support to this study.

\section{Conflicts of Interest}

The authors declare no conflicts of interest regarding the publication of this paper.

\section{References}

[1] Ogurtsova, K., da Rocha Fernandes, J.D., Huang, Y., Linnenkamp, U., Guariguata, L., Cho, N.H., et al. (2017) IDF Diabetes Atlas: Global Estimates for the Prevalence of Diabetes for 2015 and 2040. Diabetes Research and Clinical Practice, 128, 40-50. https://doi.org/10.1016/j.diabres.2017.03.024 
[2] Guariguata, L., Whiting, D.R., Hambleton, I., Beagley, J., Linnenkamp, U. and Shaw, J.E. (2014) Global Estimates of Diabetes Prevalence for 2013 and Projections for 2035. Diabetes Research and Clinical Practice, 103, 137-149. https://doi.org/10.1016/j.diabres.2013.11.002

[3] Sri Lanka Diabetes Association 2014. About Diabetes. http://diabetessrilanka.org/index.php/living-with-diabetes/about-diabetes

[4] Ranasinghe, P., Jayawardena, R. and Katulanda, P. (2015) The Facts, Figures, and Reality of the Diabetes Epidemic in Sri Lanka: A Systematic Review. International Journal of Diabetes in Developing Countries, 35, 501-513. https://doi.org/10.1007/s13410-015-0326-Z

[5] Pinidiyapathirage, M.J., Kasturiratne, A., Ranawaka, U.K., Gunasekara, D., Wijekoon, N., Medagoda, K., et al. (2013) The Burden of Diabetes Mellitus and Impaired Fasting Glucose in an Urban Population of Sri Lanka. Diabetic Medicine, 30, 326-332. https://doi.org/10.1111/dme.12013

[6] D’Souza, M.S., Karkada, S.N., Parahoo, K., Venkatesaperumal, R., Achora, S. and Cayaban, A.R.R. (2017) Self-Efficacy and Self-Care Behaviours among Adults with Type 2 Diabetes. Applied Nursing Research, 36, 25-32. https://doi.org/10.1016/j.apnr.2017.05.004

[7] Herath, H.M., Weerasinghe, N.P., Dias, H. and Weerarathna, T.P. (2017) Knowledge, Attitude and Practice Related to Diabetes Mellitus among the General Public in Galle District in Southern Sri Lanka: A Pilot Study. BMC Public Health, 17. https://doi.org/10.1186/s12889-017-4459-5

[8] Amarasekara, A.A.T.D., Fongkaew, W., Turale, S., Wimalasekara, S.W. and Chanprasit, C. (2015) Cross-Sectional Study of Glycemic Control among Adults with Type 2 Diabetes. Nursing \& Health Sciences, 17, 223-228. https://doi.org/10.1111/nhs.12179

[9] Norris, S.L., Engelgau, M.M. and Venkat Narayan, K.M.V. (2001) Effectiveness of Self-Management Training in Type 2 Diabetes: A Systematic Review of Randomized Controlled Trials. Diabetes Care, 24, 561-587. https://doi.org/10.2337/diacare.24.3.561

[10] Heisler, M., Smith, D.M., Hayward, R.A., Krein, S.L. and Kerr, E.A. (2003) How Well Do Patients' Assessments of Their Diabetes Self-Management Correlate with Actual Glycemic Control and Receipt of Recommended Diabetes Services? Diabetes Care, 26, 738-743. https://doi.org/10.2337/diacare.26.3.738

[11] Grant, R.W., Devita, N.G., Singer, D.E. and Meigs, J.B. (2003) Polypharmacy and Medication Adherence in Patients with Type 2 Diabetes. Diabetes Care, 26, 1408-1412. https://doi.org/10.2337/diacare.26.5.1408

[12] Rhee, M.K., Slocum, W., Ziemer, D.C., Culler, S.D., Cook, C.B., El-Kebbi, I.M., et al. (2005). Patient Adherence Improves Glycemic Control. The Diabetes Educator, 31, 240-250. https://doi.org/10.1177/0145721705274927

[13] Malanda, U.L., Welschen, L., Riphagen, II., Dekker, J.M., Nijpels, G. and Bot, S.D. (2012) Self-Monitoring of Blood Glucose in Patients with Type 2 Diabetes Mellitus Who Are Not Using Insulin. Cochrane Database of Systematic Reviews. https://doi.org/10.1002/14651858.CD005060.pub3

[14] Toobert, D.J., Hampson, S.E. and Glasgow, R.E. (2000) The Summary of Diabetes Self-Care Activities Measure: Results from 7 Studies and a Revised Scale. Diabetes Care, 23, 943-950. https://doi.org/10.2337/diacare.23.7.943

[15] Gao, J., Wang, J., Zheng, P., Haardörfer, R., Kegler, M.C., Zhu, Y. and Fu, H. (2013) 
Effects of Self-Care, Self-Efficacy, Social Support on Glycemic Control in Adults with Type 2 Diabetes. BMC Family Practice, 14.

https://doi.org/10.1186/1471-2296-14-66

[16] Howteerakul, N., Suwannapong, N., Rittichu, C. and Rawdaree, P. (2007) Adherence to Regimens and Glycemic Control of Patients with Type 2 Diabetes Attending a Tertiary Hospital Clinic. Asia Pacific Journal of Public Health, 19, 43-49. https://doi.org/10.1177/10105395070190010901

[17] Katulanda, P., Sheriff, M. and Matthews, D. (2009) The Diabetes Epidemic in Sri Lanka: A Growing Problem. Ceylon Medical Journal, 51, 26. https://doi.org/10.4038/cmj.v51i1.1373

[18] Katulanda, P., Constantine, G.R., Mahesh, J.G., Sheriff, R., Seneviratne, R.D.A., Wijeratne, S., et al. (2008) Prevalence and Projections of Diabetes and Pre-Diabetes in Adults in Sri Lanka-Sri Lanka Diabetes, Cardiovascular Study (SLDCS). Diabetic Medicine, 25, 1062-1069. https://doi.org/10.1111/j.1464-5491.2008.02523.x

[19] World Health Organization 2016. World Health Organization: Diabetes Country Profiles 2016. http://www.searo.who.int/srilanka/lka_en.pdf?ua=1

[20] Heidari, S., Rezaei, M., Sajadi, M., Ajorpaz, N.M. and Koenig, H. (2016) Religious Practices and Self-Care in Iranian Patients with Type 2 Diabetes. Journal of Religion and Health, 56, 683-696. https://doi.org/10.1007/s10943-016-0320-X

[21] Kumari, E.M.M.G.N., Balasooriya, P.S.P., Palamakumbura, P.K.G.M., Madhavi, A.V.P. and Isurudisi, W.G.N. (2013) An Examination of Self-Care Practices among Diabetes Mellitus Patients in Diabetic Clinic at the Teaching Hospital, Peradeniya (Annual Academic Sessions-2013/Pg. 198).

[22] Katulanda, P., Ranasinghe, P., Jayawardena, R., Sheriff, R. and Matthews, D. (2014) The Influence of Family History of Diabetes on Disease Prevalence and Associated Metabolic Risk Factors among Sri Lankan Adults. Diabetic Medicine, 32, 314-323. https://doi.org/10.1111/dme.12591

[23] Jayawardena, R., Byrne, N., Soares, M., Katulanda, P. and Hills, A. (2012) Food Consumption of Sri Lankan Adults: An Appraisal of Serving Characteristics. Public Health Nutrition, 16, 653-658. https://doi.org/10.1017/S1368980012003011

[24] Kumara, M.D.R. and Siriwardena, P.R. (2016) Knowledge, Attitudes and Practices Regarding Physical Activities among Patients with Type 2 Diabetes. Sri Lanka Journal of Diabetes Endocrinology and Metabolism, 6, 13. https://doi.org/10.4038/sjdem.v6i1.7299

[25] De Silva, A., De Silva, S., Haniffa, R., Liyanage, I., Jayasinghe, K., Katulanda, P., et al. (2016) A Survey on Socioeconomic Determinants of Diabetes Mellitus Management in a Lower Middle-Income Setting. International Journal for Equity in Health, 15. https://doi.org/10.1186/s12939-016-0363-3

[26] D’Souza, M.S., Karkada, S.N., Venkatesaperumal, R. and Natarajan, J. (2015) Self-Care Behaviours and Glycemic Control among Adults with Type 2 Diabetes. GSTF Journal of Nursing and Health Care, 2.

https://doi.org/10.5176/2345-718X_2.1.60

[27] Rahubaddha, A.N., Rajakaruna, H.I., Rajakaruna, P.A.S.Y. and Jayasinghe, S. (2016) Knowledge and Attitudes towards Proposed Graphic Warnings in a Set of Male Health Care Workers in the National Hospital of Sri Lanka. Universal Journal of Management, 4, 386-392. https://doi.org/10.13189/ujm.2016.040702 